$\stackrel{W}{=}$

Global burnals Inc.

है
GLOBAL JOURNAL OF MEDICAL RESEARCH: B

PHARMA, DRUG DISCOVERY, TOXICOLOGY \& MEDICINE

Volume 20 Issue 5 Version 1.0 Year 2020

Type: Double Blind Peer Reviewed International Research Journal

Publisher: Global Journals

Online ISSN: 2249-4618 \& Print ISSN: 0975-5888

\title{
Tablet Swasvin D Vyro (Virofight) - A Proven Solution for any Viral Infection, Immunity and Inflammation
}

By Dr. Smita Naram, Dr. Deepak Mahajan, Dr. Hemang Parekh \& Dr. Ronak Naik Abstract- Viral infections commonly affect both the respiratory tract, upper and lower. The first response of the immune system to the infection is Inflammation. This inflammation is produced by eicosanoids and cytokines, which are released by injured or infected cells. The immune modulation with Ayurvedic formulations as a possible therapeutic measures is need of the hour nowadays. The ancient Indian medicinal system of Ayurveda has a scope of treating many diseases by the theory of Rasayana, in other terms called preparations from plant or herbal source, including immune modulatory properties. In this article, we want to validate immunemodulatory, anti-inflammatory anti-viral role of Tablet Swasvin D vyro (Virofight) with the reference of some previous work done. In conclusion, we can say that Swasvin D vyro (Virofight) tablet is the best effective immune-modulatory, as it augments the cell-mediated as well as humeral mediated immune response, it is antiviral as it can inhibit replication of several viruses. It is anti-inflammatory by inhibiting various cytokine producing pathways, it has anti-oxidant and antiulcer properties.

Keywords: immunomodulator, anti-inflammatory, antiviral, D vyro, virofight.

Strictly as per the compliance and regulations of:

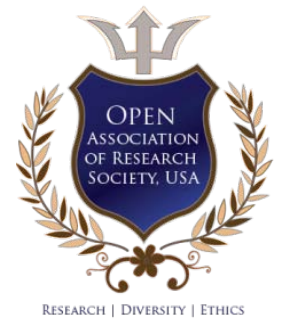

(c) 2020. Dr. Smita Naram, Dr. Deepak Mahajan, Dr. Hemang Parekh \& Dr. Ronak Naik. This is a research/review paper, distributed under the terms of the Creative Commons Attribution-Noncommercial 3.0 Unported License http://creativecommons.org/licenses/by-nc/3.0/), permitting all non-commercial use, distribution, and reproduction in any medium, provided the original work is properly cited. 


\title{
Tablet Swasvin D Vyro (Virofight) - A Proven Solution for any Viral Infection, Immunity and Inflammation
}

\author{
Dr. Smita Naram ${ }^{\alpha}$, Dr. Deepak Mahajan ${ }^{\sigma}$, Dr. Hemang Parekh ${ }^{\rho} \&$ Dr. Ronak Naik ${ }^{\omega}$
}

\begin{abstract}
Viral infections commonly affect both the respiratory tract, upper and lower. The first response of the immune system to the infection is Inflammation. This inflammation is produced by eicosanoids and cytokines, which are released by injured or infected cells. The immune modulation with Ayurvedic formulations as a possible therapeutic measures is need of the hour nowadays. The ancient Indian medicinal system of Ayurveda has a scope of treating many diseases by the theory of Rasayana, in other terms called preparations from plant or herbal source, including immune modulatory properties. In this article, we want to validate immunemodulatory, anti-inflammatory anti-viral role of Tablet Swasvin D vyro (Virofight) with the reference of some previous work done. In conclusion, we can say that Swasvin D vyro (Virofight) tablet is the best effective immune-modulatory, as it augments the cell-mediated as well as humeral mediated immune response, it is antiviral as it can inhibit replication of several viruses. It is anti-inflammatory by inhibiting various cytokine producing pathways, it has anti-oxidant and antiulcer properties.
\end{abstract}

Keywords: immunomodulator, anti-inflammatory, antiviral, $D$ vyro, virofight.

\section{BACKGROUND}

4 urvival of the fittest' is the phrase what Darwinism theory of evolution said, indicating $\checkmark$ the natural selection. In the world of microorganisms that attacks the human body in various ways, if we are fit, our immunity is good, and we can easily tackle them. The Immune system protects from infection; in short it acts as physical barrier and prevents from external pathogens like bacteria and viruses. The first response of the immune system to the infection is Inflammation. This inflammation is produced by eicosanoids and cytokines, which are released by injured or infected cells. Common cytokines include interleukins that are responsible for communication between white cells; chemokine promotes chemo taxis and interferon that have anti-viral effects ${ }^{1}$.

Viral infections commonly affect both the respiratory tract, upper and lower respiratory tract. The

Author a: Founder, Chairman and Managing Director Ayushakti Ayurveda Pvt Ltd, Bhadran nagar cross road, Malad, Mumbai-64. e-mail: drdeepakm@ayushakti.com

Author $\sigma \quad \rho$ w: Consulting Ayurveda Physician Ayushakti Ayurveda Pvt Ltd, Bhadran nagar cross road, Malad, Mumbai-64. respiratory infections are commonly classified clinically according to syndrome common cold, bronchitis, croup, pneumonia $^{2}$. The viruses mostly act through a direct invasion of epithelial cells of the respiratory mucosa. There is an increase in both leucocytes infiltration and nasal secretions, includes proteins and immunoglobulin, suggesting cytokines and immune mechanisms may be responsible ${ }^{3}$.

The immune modulation with Ayurvedic formulations as a possible therapeutic measures is need of the hour nowadays. The ancient Indian medicinal system of Ayurveda has a scope of treating many diseases by the theory of Rasayana, in other terms called preparations from plant or herbal source, including immune-modulatory properties ${ }^{4}$.The basic concept of immune modulation practiced by Ayurvedic practitioners for centuries, as it was mentioned in Ayurvedic ancient literature and Samhitas. The goal of immune enhancement achieved by Ayurveda charyas by the use of the Rasayana concept. The toxic byproducts of impaired digestion is called Aama, which clog the micro channels (Strotas) are considered as pathogenesis of Inflammation. The herbs, which improve the process of digestion, digest the Aama and purifies the micro channels is considered as an antiinflammatory. There are many such ayurvedic herbs, and herbal combinations are available in ayurvedic literature, which is being used since ancient times to treat many acute as well as chronic inflammatory diseases. When all consumed elements of the food not digested properly, it forms Aama, this forms Abnormal Digestive juice (Sama Aahar rasa), which in term produces cells that are abnormal, and these abnormal cells are virus and other pathogens ${ }^{23}$.

In this article, we want to validate the immunomodulatory, anti-inflammatory anti-viral role of Tablet Swasvin D vyro (Virofight) manufactured by Ayushakti Ayurveda Pvt Ltd with the reference of some previous work done.

\section{Name of Herbal Combination}

Tablet Swasvin D vyro (Virofight). 


\section{ili. Manufacturer}

Ayushakti Ayurveda Pvt Ltd pharmacy, Plot number 78, Stice, Musalgaon, Sinnar, Nashik- 422112.

\section{Herbal Formula}

\begin{tabular}{|c|c|c|}
\hline Ingredients & Latin name & Quantity \\
\hline Guduchi & Tinospora cardifolia & $240 \mathrm{mgs}$ \\
\hline Dadim & Punica granatum & $100 \mathrm{mgs}$ \\
\hline Madhuyashti & Glycyrrhiza glabra & $100 \mathrm{mgs}$ \\
\hline Kalmegh & Andrographis paniculata & $50 \mathrm{mgs}$ \\
\hline Kutaj & $\begin{array}{c}\text { Holerrhena } \\
\text { antidysenterica }\end{array}$ & $50 \mathrm{mgs}$ \\
\hline Sunthi & Zinziber officinale & $30 \mathrm{mgs}$ \\
\hline Vidarikand & Pueraria tuberosa & $25 \mathrm{mgs}$ \\
\hline Shatavari & Asparagus racemosus & $25 \mathrm{mgs}$ \\
\hline Godanti Bhasma & $25 \mathrm{mgs}$ \\
\hline Bhavana Dravya & $\begin{array}{r}\text { Kantakari, Tulsi patra, Jati } \\
\text { patra }\end{array}$ \\
\hline
\end{tabular}

\section{Tinospora Cardifolia}

The ethanol extract of Tinospora studied on delayed-type hypersensitivity, humoral response to sheep red sheep cells, skin allograft rejection, and phagocytic activity of the reticuloendothelial system in mice and found that Tinospora cordifolia improved the phagocytic function without affecting the humeral or cellmediated immune system ${ }^{5}$. T. cardifolia growing on Azadiracta indiaca possesses immunomodulatory potential ${ }^{6}$.T. cardifolia stimulates macrophages through TLR6 signaling and NF kappa B translocation, leading to cytokine production ${ }^{7}$.Immunomodulatory protein in the stem of $T$.cardifolia shows lymphoproliferative and macrophage activating properties ${ }^{8}$.

\section{Vi. Punica Granatum}

Active compounds in P. granatum are punicalagin and ellagic acid, the first one attenuates the inflammatory cytokine secretion, and cell adhesion of monocytes cells stimulated with airborne dust, hence can be used against oxidative stress and inflammatory response by harmful airborne dust ${ }^{9}$.P. granatum peel polyphenols inhibits LPS induced intracellular ROS production in RAW264.7 macrophages, Receptors of LPS, the mRNA and protein expression of TLR4 also the anti-inflammatory mechanism is associated with the NF$\mathrm{Kb}$ pathway ${ }^{10}$. P. granatum peel's polyphenol compounds like punicalagi, ellagic acid, and hydroxylbenzoic acid from n-butanol and ethyl acetate fractions are associated with antiviral activity against influenza virus ${ }^{11}$.When tannins like punicalagin, punicalin, strictinin, and granatin were isolated from P.granatum, granatin was an effective anti-inflammatory by decreasing the production of $\mathrm{PGE}_{2}$ in early-stage and decreasing NO production in late stage ${ }^{12}$. Polyphenols in $\mathrm{P}$. granatum may prevent virus binding to the host cell receptors by blocking the cell surface receptors of the virus surface ligands ${ }^{13}$. Punicalagin component of $P$. granatum has the virucidal capability; it inhibits influenza virus RNA proliferation, inhibits the replication of influenza RNA virus independent of the virucidal activity along with antioxidant effect ${ }^{14}$.

\section{vil. Glycyrrhiza Glabra}

A phytocomponent glycerrhizin of $\mathrm{G}$. glabra affects the cellular signaling pathways like protein kinase $\mathrm{C}$, casein kinase II, and transcription factor-like activator protein one and nuclear factor B. it's aglycone metabolite 18 glycyrrhetinic acid up-regulate expression of inducible nitrous oxide synthase and production of nitrous oxide in macrophages, which inhibits replication of several viruses. In addition, Also glycerrhizin inhibits the absorption, both during and after the absorption period, inhibits replication and penetration of SARC type coronavirus $^{15}$. Glycerrhiza uralensis ethanol extract inhibits the production of RANTES, potent chemotactic cytokine for monocytes, basophils, and T cells, typically detected in nasal secretions of patients with upper respiratory tract infections, involved in epithelial cellmediated inflammation related to viral infection like influenza virus $\mathrm{H} 1 \mathrm{~N} 1^{16}$. Glycyrrhetinic acid has proved inhibitory to the replication of some RNA and DNA viruses in vitro. Glycyrrhizin is reported to be effective against varicella-zoster virus and human immunodeficiency virus in vitro ${ }^{17}$.Glabridin and isoliquiritigenin the components of G.glabra exhibits anti-inflammatory property through inhibition of $\mathrm{PGE}_{2}$. $\mathrm{TXB}_{2}$ and, $\mathrm{LTB}_{4}$ in mammalian cell assay system ${ }^{18}$.

\section{Vili. Andrographis Paniculata}

A derivative derived from $A$ paniculata, 14-alipoyl and rographolide is effective in avian influenza A, ie.H9N2, H5N1 and human influenza A.ie. H1N1 in vitro ${ }^{(19)}$.A. paniculata shows property to inhibit secretion of RANTES by H1N1 infected A549 bronchial epithelial cells $^{20}$. Ethanol extract of $A$. paniculata and and rographolide inhibit expression of Epstein Barr virus lytic proteins, And rographolide inhibits the production of the mature viral particle. It also shows a significant effect on cellular immunological indicators. It was able to modulate the innate immune response by regulating activation of macrophages and regulate specific antibody production as well as antigen-specific IL-4 producing splenocytes ${ }^{21}$. A. paniculata enhances the WBC count, bone marrow cellularity and, $\beta$-esterase positive cells, myelosuppression found to be reversed through immunomodulatory activity, the weight of lymphoid organs, spleen and thymus were also increased $^{22}$. 


\section{Holerrhena AntidysentericA}

The alkaloids from H.antidysenterica have antidiarrheal effect as similar to the standard drug diphenoxylate, by inhibiting the production of watery fluid. Also the astringent property of alkaloids reduces denaturing production of protein tannate, which reduces the secretion from intestinal mucosa ${ }^{24}$. Hongoquercin $A$ and Hongoquercin B alkaloid derived exhibit moderate activity against Gram-positive bacteria like E.coli by passing through outer cell membrane ${ }^{25}$. The decoction of $\mathrm{H}$. antidysenterica prevents the attaching and effecting histopathology and avert the bacteria from the opportunity to establish intimate contact with host cells and, thus, it prevents from initiating the disease process $^{26}$.

\section{Zinziber Officinale}

Gingerols from Fresh ginger decreases more than $70 \%$ HRSV infection and rhinoviral infection in both A549 and HEp2 epithelial cell upper and lower respiratory tract, besides fresh ginger stimulates epithelial cells to secrete IFN- $\beta$ that contribute to the inhibition of virus replication also it has an antiinflammatory effect through inhibition of production of prostaglandins and inflammatory cytokines ${ }^{27}$. Several sesquiterpenes like beta-sesquiphellandrene were most active as an anti-viral agent against rhinovirus in vitro $^{28}$. The rhizome aqueous extract of $Z$. officinale significantly reduces the PBMC (Peripheral Blood Mononuclear Cells) proliferation assay, it also inhibits the CD 14 monocyte surface marker in human PBMC showing anti-inflammatory and anti-viral activity ${ }^{29}$.

\section{Xi. Pueraria Tuberosa}

Isoorientin was isolated from tubers of P.tuberosa was identified as a COX 2 inhibiter, which showed potent anti-inflammatory properties in vitro on mouse macrophage cell line, RAW264.7, also it is effective in reducing the inflammation in vivo on pow edema and air pouch mouse models ${ }^{30}$. Due to the effect of some isoflavones like puerarin, daidzein and genistein, $P$. tuberosa holds a promising therapeutic potential as an immunomodulator. Also $\mathrm{P}$. tuberosa extracts augmented some innate as well as humeral immune responses in rats ${ }^{31}$. Anti-inflammatory mechanism of Mangiferin extracted from P.tuberosa was confirmed via inhibiting the NF-Kb signaling, COX-1, COX-2, and inactivation of NLRP3 inflammoasomes ${ }^{32}$. Tuberosin is one of the active compounds in P.tuberosa, which have anti-inflammatory effect by inhibiting the free radical scavengers, it also has metal chelation property, and also it shows anti-oxidant property ${ }^{33}$. The ethanoic extract of P.tuberosa increases the phagocytic capacity of macrophages, inhibits both cell-mediate immunity and humeral immunity suggesting a suppressive effect on adaptive immunity without affecting the innate immune system and bone marrow proliferation ${ }^{34}$.

\section{Xil. Asparagus Racemosus}

Extract of $A$. recemosus is recommended for the use of positive immunomodulator I normal and immune-compromised broiler chicks as it augments the humoral and cell-mediated immune response providing better protection against infection by a rise in $\mathrm{HI}$ antibody $^{35}$. Steroidal saponins like Shatavarin IV, Immunoside significantly increases $\mathrm{CD}_{3}+$ and $\mathrm{CD}_{4} /$ $\mathrm{CD}_{8+}$ suggesting $\mathrm{T}$ cell activation, also the regulation of $\mathrm{Th}_{1}(\mathrm{IL}-2, \mathrm{IFN}-\mathrm{g})$ and $\mathrm{Th}_{2}$ like $\mathrm{IL}_{-4}$ cytokines suggesting activated lymphocytes ultimately showing an immunomodulatory. ${ }^{36}$ The aqueous extract of A.racemosus significantly inhibits suppression of chemotactic activity and production of $\mathrm{IL}_{-1}$, and TNF-a by murine macrophages ${ }^{37}$.

\section{Xili. Ocimum Sanctum}

O. sanctum leaves when steam distilled shows modification in humoral immune response in albino rats may be due to antibody production, the release of mediators of hypersensitivity reaction and tissue response to mediators, also fixed oils and lonolenic acid indicates significant anti-inflammatory activity against PGE-2 ${ }_{2}^{38}$. It inhibits inflammation in rats by affecting the cyclo-oxygenase and lipo-oxygenase pathways, seed oils shows maximum percentage inhabitation of leukotriene induced paw edema ${ }^{39}$.Ocimum sanctum seed oil appears to modulate both humoral and cell mediated immune response and this immunomodulatory response is mediated by GABAergic pathways ${ }^{40}$. Crude extract derived from O.sanctum leaves may inhibit the viral intracellular multiplication and masking/blocking of HA glycoprotein, terpenoid effective in virucidal and therapeutic activity, and polyphenol for prophylactic activity against influenza virus $\mathrm{H} 9 \mathrm{H} 2$ virus in ovo model, hence crude extract from the leaves of Ocimum sanctum leads to a reduction in H9N2 influenza virus in assessing the all three; virucidal, therapeutic and prophylactic activity ${ }^{41}$.

\section{Solanum Xanthocarpum}

The methanolic extract of Solanum nigrum has anti-inflammatory activity. Solanine showed the most potent inhibitory activity against the LPS-induced NO production in murine RAW264. $7^{43}$.

\section{Jasminum GRAndiflorum}

The extract of leaves of J.grandiflorum possesses the anti-ulcer potential as well as antioxidant activity. It reduces gastric fluid volume, acidity and increases the $\mathrm{pH}$ of the gastric fluids; which proves antisecretory ${ }^{44}$. Leaves extract to decrease the ulcer index, increase $\mathrm{pH}$, reduces free and total acidity, gastric 
volume proving it's an anti-secretory and hence antiulcer $^{45}$. Hydro alcoholic extract of J.grandiflorum shows Anti-inflammatory and anti-conversant acivity ${ }^{46}$.

\section{Discussion}

Nowadays, various medicinal plants and herbs are attracting interest in the development of new, more effective, and specific agents, as they may be useful in the production of phytochemicals that have activity against microbes. These plants in the form of decoctions, preparations, essential oils, and extracts widely used in ancient Indian medicine. People are preferring the use of Ayurvedic medicines as an alternate therapy for many chronic diseases as well as acute diseases nowadays. Though always there is a question, how exactly ayurvedic medicines works, by which pathway, or by which mechanism it attack on the microorganism. This manuscript was conducted just to justify the mechanism of our medicine by using some modern tools.

In conclusion, we can say Tinospora cardifolia improved the phagocytic function of the reticuloendothelial system without affecting the humeral or cell-mediated immune system (Atal CK et al. 1986, 5)T. cardifolia possesses immunomodulatory potential (Narkhede AN et al. 2014,6). It stimulates macrophages through TLR6 signaling and NF kappa B translocation, leading to cytokine production (Shyma $\mathrm{K}$ et al. 7). An active compounds in $\mathrm{P}$. granatum, punicalagin, and ellagic acid, the first one attenuates the inflammatory cytokine secretion hence can be used against oxidative stress and inflammatory response by harmful airborne dust (Soojin Parket al; 2016, 9). Peel polyphenols inhibit LPS induced intracellular ROS production in RAW264.7 macrophages, Receptors of LPS, the mRNA and protein expression of TLR4 (Du, Lin,et al; 2019, 10). punicalagi, ellagic acid and hydroxyl-benzoic acid from n-butanol and ethyl acetate fractions are associated with antiviral activity against influenza virus (Mohammad-Taghi et al. 2019,11). Tannin, like granatin, is an effective antiinflammatory by decreasing the production of $\mathrm{PGE}_{2}$ in the early-stage and decreasing $\mathrm{NO}$ production in latestage (Lee, C.J; 2016, 12). Polyphenols in P. granatum may prevent virus binding to the host cell receptors by blocking the cell surface receptors of the virus surface ligands (Howell ABet al; 2013, 13). Punicalagin component has the virucidal capability; it inhibits influenza virus RNA proliferation, inhibits the replication of influenza RNA virus independent of the virucidal activity (Haidari, M, et al.2009, 14). Glycerrhizin Up regulates expression of inducible nitrous oxide synthase and production of nitrous oxide in macrophages, which inhibits replication of several viruses, inhibits replication and penetration of SARC type coronavirus (J Cinatl et al; 2003, 15) Glycyrrhiza uralensis ethanol involved in epithelial cell-mediated inflammation related to viral infection like influenza virus H1N1 (Cristina Fiore et al. 2007, 16), Glabridin, and isoliquiritigen exhibits antiinflammatory property through inhibition of $\mathrm{PGE}_{2} \mathrm{TXB}_{2}$ and $\mathrm{LTB}_{4}$ in mammalian cell assay system (Nirmala. $\mathrm{P}$ et al. 2011, 18).14-a-lipoyl and rographolide is effective in avian influenza A, ie.H9N2, H5N1 and human influenza A,i.e. H1N1 in vitro (Wen-Wan Chao et al; 2010, 19). Andrographolide inhibit the production of mature viral particle. It also shows significant effect on cellular immunological indicators and innate immune response by regulating activation $\mathrm{IL}-4$ producing splenocytes (Churiyahet al. 2015, 21). Hongoquercin A and Hongoquercin B alkaloid derived exhibits moderate activity against Gram-positive bacteria like E.coli by passing through the outer cell membrane (Abbanat el al; 1998, 25). Gingerols from Fresh ginger decreases more than $70 \%$ HRSV infection and rhinoviral infection in both A549 and HEp2 epithelial cell upper and lower respiratory tract, secrete IFN- $\beta$ that contribute to the inhibition of virus replication also it has anti-inflammatory (J.S. Chang et al.2013, 27). Isoorientin was isolated from tubers of P.tuberosa was identified as a COX 2 inhibiter, which showed potent anti-inflammatory properties in vitro on mouse macrophage cell line, RAW264.7 (Kotha Anilkumar et al. 2017,30). Isoflavones like puerarin, daidzein, and genistein, P. tuberosa are immunomodulator. Also P. tuberosa extracts augmented some innate as well as humeral immune responses in rats (A. K. Majiet al, 31)Extract of A.recemosus is recommended for the use as positive immunomodulator I as it augments the humoral and cell mediated immune response (Kumari R et al.2012,35). Steroidal saponins like Shatavarin IV, Immunoside significantly increases $\mathrm{CD}_{3}+$ and $\mathrm{CD}_{4} / \mathrm{CD}_{8+}$ suggesting $\mathrm{T}$ cell activation, also regulation of $T h_{1}\left(\mathrm{IL}_{-2}, \mathrm{IFN}-\mathrm{g}\right)$ and $\mathrm{Th}_{2}$ like $\mathrm{IL}_{-4}$ cytokines suggesting activated lymphocytes ultimately suggesting immunomodulatory effect of A.recemosus (Manish Gautam et al. 2009,36). Sanctum leaves when steam distilled shows modification in humoral immune response in albino rats due to antibody production, release of mediators of hypersensitivity reaction and tissue response to mediators, also fixed oils and Ionolenic acid indicates significant anti-inflammatory activity against PGE- ${ }_{2}$ (S Mondal et al;2009). It inhibits inflammation in rats may be it affects the cyclooxygenase and lipo-oxygenase pathways (P.K Mediratta et al. 2002).

\section{Result}

We can say that Swasvin D vyro (Virofight) tablet is the best effective immunomodulator, as it augments the cell mediated as well as humeral mediated immune response, it is antiviral as it can inhibit replication of several viruses, and it is anti-inflammatory by inhibiting various cytokine producing pathways, it has anti-oxidant and antiulcer properties. 


\section{References Références Referencias}

1. Chemokines and chemokine receptors: their manifold roles in homeostasis and disease. Cell Mol Immunol. 2004; 1(2):95-104.

2. Infectious-diseases respiratory-viruses/overview-ofviral-respiratory-infections https://www.msdmanuals. com/professional

3. Dasaraju PV, Liu C. Infections of the Respiratory System. In: Baron S, editor. Medical Microbiology. 4th edition. Galveston (TX): University of Texas Medical Branch at Galveston; 1996. Chapter 93.

4. Rege NN, Thatte UM, Dahanukar SA. Adaptogenic properties of six rasayana herbs used in Ayurvedic medicine. Phytother Res. 1999; 13(4):275-291. doi: 10.1002/(SICI)1099-1573(199906)13:4<275::AIDPTR510>3.0.CO;2-S

5. Atal CK, Sharma ML, Kaul A, Khajuria A. Immunomodulating agents of plant origin. I: Preliminary screening. J Ethnopharmacol. 1986; 18(2):133-141. doi:10.1016/0378-8741(86)90025-5

6. Narkhede AN, Jagtap SD, Kasote DM, Kulkarni OP, Harsulkar AM. Comparative immunomodulation potential of Tinospora cordifolia (Willd.) Miers ex Hook. F., Tinospora sinensis (Lour.) Merrill and Tinospora cordifolia growing on Azadirachta indica A. Juss. Indian J Exp Biol. 2014; 52(8):808-813.

7. Shyma K. Latheef Ameliorative effects of Withania somnifera, Azadirachta indica, Tino- spora cordifolia and $E$ care Se herbal preparations on chicken infectious anaemia virus induced haematological changes in chicks and their live body weights ISSN: 2230-9799Vol. 3, Issue 4, Page 172-182.

8. IvanAranha ${ }^{1}$ Fatima Clement $^{2}$ Yeldur P.Venkatesh Immunostimulatory properties of the major protein from the stem of the Ayurvedic medicinal herb, guduchi (Tinosporacordifolia) https://doi.org/10. 1016/j.jep.2011.11.013Get rights and content.

9. Soojin Park, Anti-Inflammatory Effects of Pomegranate Peel Extract in THP-1 Cells Exposed to Particulate Matter PM10, Evidence-Based Complementary and Alternative Medicine, Received 5 January 2016; Revised 14 April 2016; Accepted 18 April 2016.

10. Du, Lin \& Li, Jianke \& Zhang, Xitong \& Wang, Lifang \& Zhang, Weimin \& Yang, Mi \& Hou, Chen. (2019). Pomegranate peel polyphenols inhibits inflammation in LPS-induced RAW264.7 macrophages via the suppression of TLR4/NF-kB pathway activation. Food \& Nutrition Research. 63. 10.29219/ fnr.v63.3392.11.

11. Mohammad-Taghi Moradi 1 , Ali Karimi 2*, Mehrdad Shahrani 2, Leila Hashemi 3, and Mohammad-Saleh Ghaffari-Goosheh 2 Anti-Influenza Virus Activity and Phenolic Content of Pomegranate (Punica granatum L.) Peel Extract and Fractions,Avicenna $J$ Med
Biotech 2019; 11(4): 285-291Vol. 11, No. 4, October-December 2019

12. Lee, C.J. \& Chen, Lih-Geeng \& Liang, Wen-Li \& Wang, Ching-Chiung. (2010). Anti-inflammatory effects of Punica granatum Linne in vitro and in vivo. Food Chemistry. 118. 315-322. 10.1016/j.foodchem. 2009.04.123.

13. Howell AB, D'Souza DH. The pomegranate: effects on bacteria and viruses that influence human health. Evid Based Complement Alternat Med. 2013; 2013:606212. doi:10.1155/2013/606212.

14. Haidari, M., et al., Pomegranate (Punica granatum) purified polyphenol extract inhibits influenza virus and has a synergistic.... Phytomedicine (2009), doi:10.1016/j.phymed.2009.06.002.

15. J Cinatl, B Morgenstern, G Bauer, P Chandra, H Rabenau, H W Doerr, Glycyrrhizin, an active component of liquorice roots, and replication of SARS-associated coronavirus Lancet 2003; 361: 2045-46THE LANCET • Vol 361 • June 14, 2003 • www.thelancet.com.

16. Cristina Fiore Michael Eisenhut, Antiviral effects of Glycyrrhiza species, PHYTOTHERAPY RESEARCH Phytother. Res. 22, 141-148 (2008) Published online 20 September 2007 in Wiley Inter Science (www.interscience.wiley.com) DOI: 10.1002/ptr.2295 https://doi.org/10.1002/ptr.2295.

17. LALITA BADAMIn vitro studies on the effect of glycyrrhizin from Indian Glycyrrhiza glabra Linn on some RNA and DNA viruses, Indian Journal of Pharmacology 1994; 26: $194-199$.

18. Nirmala, PAnti-inflammatory and anti-bacterial activities of Glycyrrhiza glabra L.Journal of Agricultural Technology 2011 Vol. 7(3): 815-823

19. Wen-Wan Chao and Bi-Fong Lin*Review Isolation and identification of bioactive compounds in Andrographis paniculata (Chuanxinlian)Chao and Lin Chinese Medicine 2010, 5:17.

20. Han-ChiehKo ${ }^{a}$ The effect of medicinal plants used in Chinese folk medicine on RANTES secretion by virus-infected human epithelial cells, Journal of Ethnopharmacology Volume 107, Issue 2, 19 September 2006, Pages 205-210 https://doi.org/ 10.1016/j.jep.2006.03.004.

21. Churiyah, Antiviral and Immunostimulant Activities of Andrographis paniculata HAYATI Journal of Biosciences April 2015 Vol. 22 No. 2, p 67-72 EISSN: 2086-4094, DOI: 10.4308/hjb.22.2.67.

22. Sheeja K, Kuttan G. Ameliorating effects of Andrographis paniculata extract against cyclophosphamide-induced toxicity in mice. Asian Pac J Cancer Prev 2006; 7:609-14.

23. Dnyaneshwar Kantaram Jadhav. "Virus: An Ayurvedic View". Acta Scientific Medical Sciences 2.7 (2018): 27-29.

24. Antibacterial and antidiarrhoeal effects of alkaloids of Holarrhena antidysenterica WALL, Indian journal 
of Experimental Biology, Vol. 42, June 2004,pp. 589.594.

25. Abbanat el al Hongoquercins, New Antibacterial Agents from the Fungus LL-23G227: Fermentation and Biological Activity, The Journal of Antibiotics/51 (1998) 8.

26. Poonam G Daswani, Investigation of the Antidarrhoeal Activity of Holarrhena Antidysenterica, Indian Journal of Pharmaceutical Sciences. MarchApril 2002.

27. J.S. Chang et al. Fresh ginger (Zingiber officinale) has anti-viral activity against human respiratory syncytial virus in human respiratory tract cell lines Journal of Ethnopharmacology 145 (2013) 146-151

28. Denyer CV, Jackson P, Loakes DM, Ellis MR, Young DA. Isolation of antirhinoviral sesquiterpenes from ginger (Zingiber officinale). J Nat Prod. 1994; 57(5):658-662. doi:10.1021/np50107a017

29. Amit Gupta, Immuno pharmacological Activity of Zingiber officinale on Human Peripheral Blood Mononuclear Cells, Asian J. Med. Pharm. Res. 5(2): 13-17, June 25, 2015.

30. Kotha Anilkumar, Evaluation of Anti-Inflammatory Properties of Isoorientin Isolated from Tubers of Pueraria tuberosa, Hindawi Oxidative Medicine and Cellular Longevity Volume 2017, Article ID 5498054, 10 pages https://doi.org/10.1155/2017/5498054.

31. A. K. Maji, S. Mahapatra, and D. Banerjee, "In-vivo immunomodulatory potential of standardized pueraria tuberosa extract and its isoflavonoids," International Journal of Pharmacy and Pharmaceutical Sciences, vol. 6, no. 1, pp. 861867, 2014.

32. Pandey N, Yadav D, Pandey V, Tripathi YB. Antiinflammatory effect of Pueraria tuberosa extracts through improvement in activity of red blood cell anti-oxidant enzymes. Ayu. 2013; 34(3):297-301. doi:10.4103/0974-8520.123131.

33. Pandey, Nidhi \& Tripathi, Yamini Bhusan. (2010). Antioxidant activity of tuberosin isolated from Pueraria tuberose Linn. Journal of inflammation (London, England). 7. 47. 10.1186/1476-9255-7-47.

34. Jignesh Patel, Immunomodulatory activity of ethanolic extract of Pueraria Tuberosa D.C., International Journal of Scientific \& Engineering Research, Volume 7, Issue 11, November-2016 ISSN 2229-5518.

35. Kumari R, STUDY ON THE IMMUNOMODULATORY EFFECT OF HERBAL EXTRACT OF ASPARAGUS RACEMOSUS WILLD. IN BROILER CHICKS, GJRMI, Volume I, Issue I, January 2012, $1-6$

36. Manish Gautam, Immunomodulatory activity of Asparagus racemosus on systemic Th1/Th2 immunity: Implications for immunoadjuvant potential, Journal of Ethnopharmacology Volume 121, Issue 2, 21 January 2009, Pages 241-247.
37. Devasagayam, T P A, Sainis, K B, Immune system and antioxidants, especially those derived from Indian medicinal plants, IJEB Vol.40(06) [June 2002]

38. Gupta, S K,Prakash, Jai, Srivastava, Sushma, Validation of traditional claim of Tulsi, Ocimum sanctum Linn. as a medicinal plant, IJEB Vol.40(07) [July 2002].

39. S Mondal, The science behind sacredness of Tulsi (Ocimum sanctum Linn.), Indian J Physiol Pharmacol 2009; 53 (4) : 291-306.

40. P. K Mediratta, Evaluation of immunomodulatory potential of Ocimum sanctum seed oil and its possible mechanism of action, Journal of Ethnopharmacology Volume 80, Issue 1, April 2002, Pages 15-20.

41. SS Ghoke, Ghoke, S.S., Sood, R., Kumar, N. et al. Evaluation of antiviral activity of Ocimum sanctum and Acacia Arabica leaves extracts against H9N2 virus using embryonated chicken egg model. BMC Complement Altern Med 18, 174 (2018). https://doi.org/10.1186/s12906-018-2238-1

42. YS Rani, A review on Solanum nigrum, WORLD JOURNAL OF PHARMACY AND PHARMACEUTICAL SCIENCES SJIF Impact Factor 6.647 Volume 6, Issue 12, 293-303

43. Gu XY, Shen XF, Wang L, et al. Bioactive steroidal alkaloids from the fruits of Solanum nigrum. Phytochemistry. 2018; 147:125-131. doi: 10. 1016/j.phytochem.2017.12.020.

44. IM. Umamaheswari Antiulcer and in vitro antioxidant activities of Jasminum grandiflorum L.Journal of Ethnopharmacology Volume 110, Issue 3, 4 April 2007, Pages 464-470.

45. Mahajan Nilesh et al. EVALUATION OF ANTI-ULCER POTENTIAL OF LEAVES OF JASMINUM GRANDIFLORUM L,IJPS, Sept-December 2009 | Vol. 1 | Issue 2 |247-249.

46. Gupta RK, Reddy PS. Antinociceptive and anticonvulsant activities of hydroalcoholic extract of Jasminum grandiflorum (jasmine) leaves in experimental animals. Pharmacognosy Res. 2013;5(4):286-290. doi:10.4103/0974-8490.118813. 